\title{
Pressure Support Breaths Triggered by Total Artificial Heart in Invasive and Non-Invasive Mechanical Ventilation
}

\author{
Amit Prasad, MD, ${ }^{1}$ Kai Singbartl, $\mathrm{MD},{ }^{1}$ Behzad Soleimani, $\mathrm{MD},{ }^{1}$ Christoph Brehm, MD,${ }^{1}$ \\ Ali Ghodsizad, $\mathrm{MD}^{2}$
}

${ }^{1}$ Heart and Vascular Institute, Penn State Milton S. Hershey Medical Center, Penn State College of Medicine, Hershey, Pennsylvania, USA; ${ }^{2}$ Miami Transplant Institute, University of Miami, Jackson Memorial Hospital, Miami, Florida, USA

\section{ABSTRACT}

Because of the risks associated with extended mechanical ventilation, it is desirable to extubate patients as early as possible. However, weaning patients from mechanical ventilation too early has risks associated with it as well. Thus, it is important to note that in the two cases presented here, pressure-supported breaths were falsely triggered by a patient's a Syncardia ${ }^{\circledR}$ total artificial heart (TAH), influencing decisions about weaning the patient from mechanical ventilation.

\section{INTRODUCTION}

The Syncardia ${ }^{\circledR}$ total artificial heart (TAH) is now an option for patients with both right and left heart failure, and who are therefore not candidates for a left ventricular assist device (LVAD). It provides pulsatile blood flow through the body using two pneumatic pumps that can generate upwards of 10 liters of flow. We describe two different cases in which these pneumatic pumps triggered pressure support breaths in invasive and non-invasive mechanical ventilation.

\section{CASE REPORT}

The first case involved a 44-year-old male with history of non-ischemic dilated cardiomyopathy who had a HeartWare ${ }^{\circledR}$ LVAD placed due to left ventricular failure, underwent right ventricular failure, and was unable to be weaned off of inotropic support, had a Syncardia ${ }^{\circledR}$ TAH placed about a month after LVAD placement. His post-operative course was complicated by delayed tamponade 6 days after placement, resulting in re-exploration of the mediastinum. After this surgery, the patient was weaned and extubated to nasal cannula a few days later. However, after extubation he required noninvasive bilevel positive airway pressure (BiPAP) therapy for atelectasis. Usually, patients requiring BiPAP are placed on a Respironics Vision $60^{\circledR}$ non-invasive machine with flow

Received fune 6, 2017; received in revised form fuly 6, 2017; accepted August $25,2017$.

Correspondence: Amit Prasad, MD, Department of Cardiac Surgery, Heart and Vascular Institute, Penn State Milton S. Hershey Med Center, Penn State College of Medicine, 500 University Dr., Hershey, PA 17033; (e-mail: aprasad@hmc.psu.edu). trigger with pressure control of $10 \mathrm{cmH}_{2} \mathrm{O}$ and $5 \mathrm{cmH}_{2} \mathrm{O}$ of positive end expiratory pressure. However, in this case the patient was switched to a Servo ${ }^{\circledR}$ I non-invasive ventilator to deliver pressure support breaths via a pressure trigger because his TAH falsely caused pressure supports to be given, thus falsely elevating his minute ventilation.

The second case was a 48-year-old female with nonischemic dilated cardiomyopathy who was transferred to our hospital in biventricular failure, and who underwent an implantation of a Syncardia ${ }^{\circledR}$ total artificial heart. Her

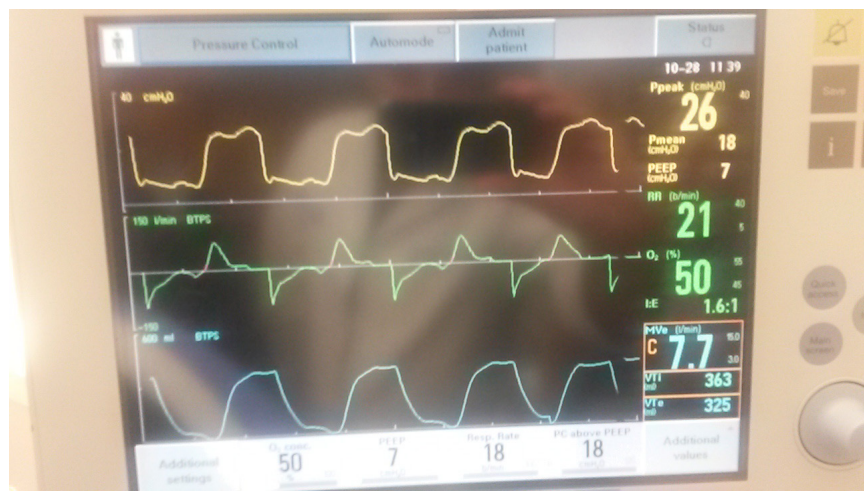

Figure 1. Patient with elevated minute ventilation due to pressure support breaths triggered by FAH.

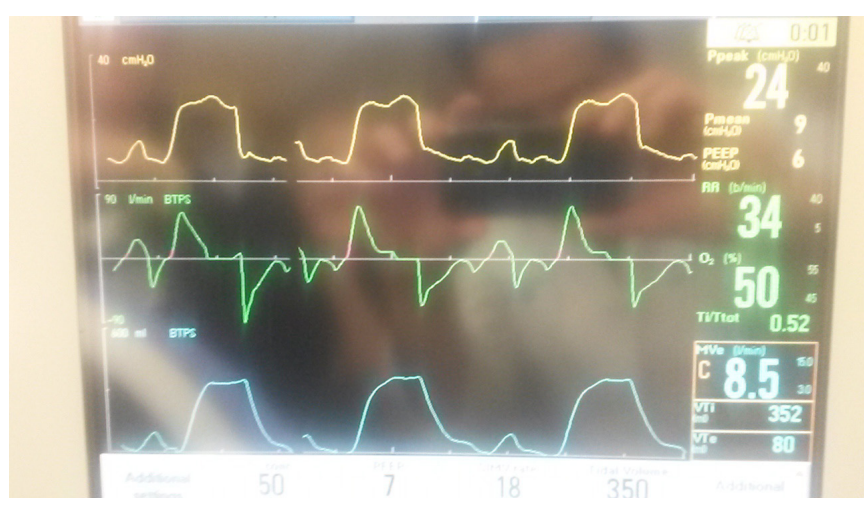

Figure 2. Patient after correction of elevated minute ventilation by changing from a flow trigger of -3 liters per minute to a pressure trigger, initially at $-1 \mathrm{cmH}_{2} \mathrm{O}$, then increased to $-3 \mathrm{cmH}_{2} \mathrm{O}$. 
post-operative course was mainly uneventful and was extubated 36 hours after the operation. However, while weaning her from the ventilator, it was discovered when the patient was on pressure control with pressure support that she had an elevated minute ventilation. This was investigated and it was discovered that the TAH was triggering pressure support breaths (Figure 1). This was corrected by changing her from a flow trigger of -3 liters per minute to a pressure trigger that was initially at $-1 \mathrm{cmH}_{2} \mathrm{O}$, and then increased to $-3 \mathrm{cmH}_{2} 0$ (Figure 2).

\section{DISCUSSION}

Heart failure affects about 5 million people in the United States and more than 20 million people worldwide [Fang 2008]. The limit of hearts available for transplant creates a need for a bridge to transplant, and the Syncardia ${ }^{\circledR} 70$ milliliter TAH has been used successfully as such. When compared to HeartMate ${ }^{\circledR}$, survival to transplant with a TAH was about $10 \%$ improved, and overall survival was $11 \%$ improved [Copeland 2004]. The Syncardia ${ }^{\circledR}$ TAH is a pulsatile, biventricular, pneumatic system that can produce up to 9 liters per minute of cardiac output due to its $27 \mathrm{~mm}$ inflow valve [Copeland 2004; Copeland 2003]. Adverse effects of TAH include reoperation (25\%), stroke (8\%), embolism (8\%), and drive line infections. Causes of death on TAH include multiple organ failure, sepsis and pneumonia [Copeland 2004].

Prolonged ventilation has been linked to many cardiac and pulmonary complications. Positive pressure ventilation decreases preload to the right ventricle [Jardin 1984; Marini 1980], which would lead to hypovolemia in a TAH patient. Furthermore, prolonged ventilation can lead to many pulmonary complications including barotrauma, pneumonia, acute lung injury, and tracheal stenosis [Bernarde 1994; Parker 1990; Dreyfuss 1985; Taylor 1967]. Because these pulmonary complications can be life threatening, it is essential to extubate patients as early as possible. There are several ways to wean patients from the ventilator, but they all involve a spontaneous breathing trial on continuous positive airway pressure (CPAP) with pressure support breaths [McConville 2012; Epstein 1997].

Early mobilization has been a consistent goal with patients with LVADs and TAH. It has been reported that patients have been mobilized still being ventilator dependent. It is essential in these patients that they do not suffer from the common complications of being on bed rest, and it has been proven that early mobilization helps with endurance, decreases the time of being ventilator dependence, and leads to more favorable outcomes at time of heart transplantation [Morrone 1996; Stiller 2000].

We describe two patients with total artificial hearts, whose devices trigger a pressure supported breath in both noninvasive and invasive mechanical ventilation. Even though the exact mechanism is unclear, it could be due to the pressure generated by the mechanical heart due to its pneumatic pumps. It has been reported that these pumps can generate velocities upwards of $1.8 \mathrm{~m} / \mathrm{s}$ [Slepian 2013], which could generate enough pressure to trigger the ventilator to give a pressure supported breath. This is important because this could falsely influence the decision that the patient is able to be weaned from the ventilator, and could lead to other pulmonary complications and increased morbidity and mortality [Epstein 1997]. It is also important to recognize that both these patients had 70 milliliter TAH and that there is a smaller version for smaller patients that has a capacity of 50 milliliters. Because of the smaller chest wall, but with the same pneumatic potential, these patients could be at higher likelihood to accidently trigger a pressure supported breath while weaning from mechanical ventilation.

\section{REFERENCES}

Bernarde GR, Artigas A, Brigham KL, et al. 1994. The AmericanEuropean consensus conference on ARDS: definitions, mechanisms, relevant outcomes, and clinical trial coordination. Am J Repsir Crit Care Med 149: 818-24.

Copeland JG, Arabia FA, Tsau PH, et al. 2003. Total artificial hearts: bridge to transplantation. Cardiol Clin 21: 101-13.

Copeland JG, Smith RG, Arabia FA, et al. 2004. Total artificial heart bridge to transplant: a 9-year experience with 62 patients. J Heart Lung Transplant 23: 823-31.

Dreyfuss D, Bassest G, Soler P, Saumon G. 1985 Intermittent positivepressure hyperventilation with high inflation pressures produces pulmonary microvascular injury in rats. Am Rev Repsir Dis 132: 880-4.

Epstein SK, Ciubotrau RL, Wong JB. 1997. Effect of failed extubation on the outcome of mechanical ventilation. Chest 112: 186-92

Fang J, Mensah GA, Croft JB, et al. 2008. Heart failure-related hospitalization in the US, 1979-2004. J Am Coll of Cardiol 52: 428-34.

Jardin F, Farcot JC, Guéret P, Prost JF, Ozier Y, Bourdarias JP. 1984. Echocardiographic evaluation of ventricles during continuous positive pressure breathing. J Appl Physiol Respir Environ Exerc Physiol. 56: 619-27.

Marini JJ, Culver BH, Butler J. 1981. Mechanical effect of lung distention with positive pressure on cardiac function. Am Rev Repsir Dis 124: 382-6.

McConville JF, Kress JP. 2012. Weaning patients from the ventilator. N Engl J Med 367: 2233-9.

Morrone TM, Buck LA, Catanese KA, et al. 1996. Early progressive mobilization of patients with left ventricular assist devices is safe and optimizes recovery before heart transplantation. J Heart Lung Transplant 15: 423-9.

Parker JC, Hernandez LA, Longenecker GL, Peevy K, Johnson W. 1990. Lung edema caused by high peak inspiratory pressure in dogs: role of microvascular filtration pressure and permeability. Am Rev Respir Dis 142: $321-8$.

Slepian MJ, Almenu Y, Girdhar G, et al. 2013. The Syncardia $\left({ }^{\mathrm{TM}}\right)$ total artificial heart: in vivo, in vitro, and computational modeling studies. J Biomech 46: 266-75.

Stiller K. 2000. Physiotherapy in intensive care: towards an evidencebased practice. Chest 118: 1801-13.

Taylor RR, Caell JW, Sonnenblick EH, Ross J Jr. 1967. Dependence of ventricular distensibility on filling of the opposite ventricle. Am J Physiol 213: 711-8. 